\title{
Short communication: Effect of pomegranate-residue supplement on Cryptosporidium parvum oocyst shedding in neonatal calves
}

\author{
S. Weyl-Feinstein, ${ }^{*}{ }^{1}$ A. Markovics, $\ddagger$ H. Eitam, ${ }^{\star} \dagger$ A. Orlov, ${ }^{*}$ M. Yishay, ${ }^{*}$ R. Agmon, ${ }^{*}$ J. Miron, $\S ~ I . ~ I z h a k i, \dagger$ \\ and A. Shabtay* \\ *Department of Ruminant Science, Institute of Animal Science, Newe Ya'ar Research Center, Agricultural Research Organization, PO Box 1021, \\ Ramat Yishay 30095, Israel \\ †Department of Evolutionary and Environmental Biology, Faculty of Sciences, University of Haifa, 31905 Haifa, Israel \\ ‡Department of Parasitology, Kimron Veterinary Institute, PO Box 12, Bet-Dagan 50250, Israel \\ $\S$ Department of Ruminant Science, Institute of Animal Science, Agricultural Research Organization, PO Box 6, 50250, Bet-Dagan, Israel
}

\section{ABSTRACT}

Cryptosporidium parvum is considered one of the most common enteropathogens, responsible for the high incidence of diarrhea and deleterious implications on immunity and health in neonatal calves. The pomegranate is well known for its health-promoting properties. Two experiments were designed to test the antiparasitical and antidiarrheal effects of concentrated pomegranate extract (CPE) supplement in milk in neonatal Holstein calves. Forty-one calves were randomly divided into control $(\mathrm{n}=20)$ and treatment $(\mathrm{n}=21)$ groups. For the first experiment, the treatment group was supplemented with $3.75 \%$ CPE in the daily milk ration, between 3 and $14 \mathrm{~d}$ of age, whereas the control group received only milk. Fecal samples were collected between d 5 and 13 to quantify Cryptosporidium oocysts, and the duration and intensity of diarrhea were evaluated. Reduced fecal oocyst count and diarrhea intensity and duration were revealed in the $3.75 \% \mathrm{CPE}$ calves. No difference was noted in average daily gain between groups. In a second experiment, which was designed to test the effect of a lower CPE concentration ( $0.6 \%$ of daily milk allocation), no effects on fecal oocyst count and average daily gain were observed. However, compared with control, the lower CPE group was characterized by a shorter duration of diarrhea and higher weight gain among males at $14 \mathrm{~d}$ of age. These results suggest that the CPE supplement-to-calf milk ratio may potentially alleviate intestinal morbidity caused by Cryptosporidium.

Key words: Cryptosporidium parvum, cryptosporidiosis, neonatal diarrhea, tannins, concentrated pomegranate extract

Received June 13, 2013.

Accepted May 19, 2014

${ }^{1}$ Corresponding author: sarah@volcani.agri.gov.il

\section{Short Communication}

The apicomplexan protozoan parasite Cryptosporidium parvum is considered one of the most common enteropathogens affecting neonatal calves (Geurden et al., 2006; Santín et al., 2008); it causes enteric infection and diarrhea in many species of mammals (O'Donoghue, 1995) and is a well-known cause of diarrhea in humans and in calves younger than 1 mo (Silverlås et al., 2009). Worldwide studies indicate that within herds its prevalence ranges from 53 to $100 \%$ (Lassen et al., 2009; Silverlås et al., 2010). Pathogenesis results from a fecal-oral route transmission preceded by sporozoites encysting the oocysts, whereupon the parasite invades the epithelium resulting in its destruction, villus atrophy, and microvillus shortening (de Graaf et al., 1999); consequently, diarrhea is a typical outcome.

Infection starts as early as $3 \mathrm{~d}$ of age (Snodgrass et al., 1980; Xiao and Herd, 1994), peaks at 6 to 15 d of age (Quílez et al., 1996), followed by a gradual reduction of oocyst shedding (Fayer et al., 1998) during the preweaned period (Xiao, 2010). Oocyst numbers can reach the magnitude of $10^{6}$ to $10^{7} / \mathrm{g}$ of feces (Current, 1985); however, even small numbers of oocysts are sufficient to infect the gut (De Waele et al., 2010), causing diarrhea, often complicated by metabolic acidosis and electrolyte imbalances (Kasari, 1999), that may lead to dehydration and death (Chen et al., 2003).

Effective therapy for cryptosporidiosis is limited (Cevallos et al., 2000), so the main mode of action remains preventive hygiene management. Cryptosporidium parvum oocysts are highly resistant to environmental stresses and to many disinfectants (Harp and Goff, 1998; De Waele et al., 2010). As C. parvum is an enteropathogen, the supplement of plant-originated substances that possess health-promoting traits may target it locally, without the need for absorption.

The pomegranate fruit represents such an alternative. In recent years a growing awareness of the beneficial effects of pomegranate consumption in the human 
diet has triggered the development of a pomegranate products industry. In turn, this has led researchers to investigate the effects of these industrial by-products on ruminant health and production (Shabtay et al., 2008, 2012; Oliveira et al., 2010; Jami et al., 2012). Among the variety of its qualities, peels of Punica granatum are well documented as possessing gastro-protective (Ajaikumar et al., 2005), antidiarrheal (Nagaraju and Rao, 1990; Das et al., 1999), antiparasitical (Tripathi and Singh, 2001), and antihelmintic (Prakash et al., 1980; Naovi et al., 1991) properties, specifically against cattle pathogens such as tapeworms and Giardia (Hukkeri et al., 1993; Ponce-Macotela, 1994). To meet these needs, taking into account the origin of domestic cattle from free-ranging herbivores, tannins and other possible antimicrobial factors in plants, when added to milk, may be helpful for treating pathogens and parasites that cause scours. Hence, it may be very important for domestic calves to start consuming tannins at an early age to help reduce the effects of pathogens and parasites. A recent study demonstrated antidiarrheal and anticryptosporidial effects of the pomegranate peel on infected mice (Al-Mathal and Alsalem, 2012). However, to the best of our knowledge, no study has been designed to examine the activity of concentrated pomegranate extract (CPE) against cryptosporidiosis in neonatal calves. Thus, the current study was aimed at investigating the effect of dietary supplementation of CPE in milk on Cryptosporidium oocyst shedding in Holstein calves reared in commercial farms.

A field experiment during the summer season ( $\mathrm{Au}-$ gust-September 2011, at temperatures and moisture levels ranging between 24 and $31^{\circ} \mathrm{C}$ and $60-90 \%$, respectively) was performed in an Ein Ha'mifratz (Israel) dairy farm (1,000 milking cows). Forty-one Holstein calves, born and reared on the farm, were randomly assigned in a blinded manner to control $(\mathrm{n}=20)$ and treatment $(\mathrm{n}=21)$ groups. Nine females were included in every group and the rest were males. Enrollment criteria included single-born, full-term calves with over $40 \mathrm{~kg}$ of BW at birth. The average BW at calving were $43.9 \pm 3.5$ and $44.4 \pm 3.1 \mathrm{~kg}$ for the control and treatment calves, respectively. Calves were fed pooled cow colostrum milk from the day of calving up to $3 \mathrm{~d}$. At 3 $\mathrm{d}$ of age they were transferred to a shaded nursing barn and housed in individual pens $(2 \times 1 \mathrm{~m})$ until weaning. Calves were nursed with $400 \mathrm{~g}$ of Health Halavit milk powder (Koffolk s.n 46002470, Phibro, Maabarot, Israel) mixed in $2 \mathrm{~L}$ of water once daily up to $3 \mathrm{wk}$ of age. The milk powder containing $23 \%$ protein and $15 \%$ fat was then replaced by Halavit Platina (23\% protein, $18 \%$ fat; Koffolk, Phibro). In addition, calves were offered ad libitum suckling starter (cat\# 7820, Milobar, Israel) containing $17 \% \mathrm{CP}, 3 \%$ fat, $7 \% \mathrm{CF}, 7 \%$ ash, $1 \%$
$\mathrm{Ca}, 0.4 \% \mathrm{P}$, and $0.7 \% \mathrm{NaCl}$ on a $\mathrm{DM}$ basis and had free access to fresh water. The treatment group received $\mathrm{CPE}$ in milk once daily in increasing dosages (percent of milk daily ration) between 3 and $13 \mathrm{~d}$ of age: $1.25 \%$ between 3 and $4 \mathrm{~d}, 2.5 \%$ between 5 and $6 \mathrm{~d}$, and $3.75 \%$ between 7 and $13 \mathrm{~d}$ of age [high CPE (H-CPE) experiment].

Following the veterinarian's instructions and due to the high incidence of diarrhea morbidity on the farm (and the concern of mixed bacterial infection), a welltrained worker in the crew treated scouring calves with antibiotics (gentamicin at $4 \mathrm{~mL} / 50 \mathrm{~kg}$ i.m. once daily for $3 \mathrm{~d}$ ). To gain insight into the minimal effective dose of CPE that would reduce fecal oocyst count (FOC) and diarrhea intensity, we designed a second similar experiment, in which calves received $0.6 \%$ of an extract that contained $12.35 \%$ polyphenols [lower CPE (L-CPE) experiment]. The L-CPE calves were born and reared in Yagur dairy farm (300 milking cows), Israel (in winter time, December 2011-February 2012, at temperatures and moisture levels ranging between 8 and $20^{\circ} \mathrm{C}$ and $53 \%$, respectively). Calves were fed cow milk without grain supplements until they were 3 wk old. A scouring calf was given a dietary supplement (Pecto-lit+, s. n 44110080, Koffolk, Maabarot) in addition to electrolyte supplements. In both experiments, calves were weighed on the day of calving and at weaning $(54 \mathrm{~d})$ and their ADG during this period was calculated. Fecal samples were taken daily from both groups between 5 and $13 \mathrm{~d}$ of age to calculate FOC. The samples were rectally recovered from calves under sanitary conditions and kept refrigerated at $4^{\circ} \mathrm{C}$ until the diagnosis and quantification of Cryptosporidium oocysts in the parasitological laboratories of the National Veterinary Institute, Beit Dagan, Israel. Fecal samples were analyzed by a quantitative method to determine the number of oocysts per gram of feces; after mixing the sample, $5 \mathrm{~g}$ of fecal material was thoroughly mixed in $20 \mathrm{~mL}$ of tap water to obtain a homogeneous suspension that was strained through a 100-mesh sieve. Ten microliters of this filtrate was deposited as a drop on a slide, air-dried, and fixed in methanol for $1 \mathrm{~min}$. The slide was stained with concentrated carbol fuchsin for 30 min, rinsed with water, and decolorized in $10 \%$ sulfuric acid for about $10 \mathrm{~s}$. After rinsing with water, the slides were counterstained with $0.5 \%$ brilliant green for $5 \mathrm{~min}$. The entire area of the smear was examined with a $400 \times$ objective lens and the red-stained oocysts were counted. If too many oocysts were present to be accurately counted, the sample was diluted 10-fold, reprocessed and re-examined. Oocysts per gram were calculated by multiplying the result by the dilution factor (Grinberg et al., 2002). To evaluate the occurrence and intensity of diarrhea in the $\mathrm{H}-\mathrm{CPE}$ experiment, a scale of 1 to 5 
was used: fecal consistency was scored as 1 when firm, 2 when soft or of moderate consistency, 3 for runny or mild diarrhea, 4 for watery and profuse diarrhea, and 5 when highly watery (Larson et al., 1977; Magalhães et al., 2008). In the L-CPE experiment, a score of 1 to 4 was conducted, and scores of 5 were omitted due to the difference in diarrhea intensity. We considered the calves to have clinical diarrhea if a calf was scored $\geq 3$. The duration of diarrhea and its intensity were inspected in a blinded manner by 3 well-trained workers, working under the inspection of the veterinarian. The duration of diarrhea was determined during the period of score $\geq 3$. The CPE of the pomegranate cultivar 'Wonderful' was supplied by Gan Shmuel Food Ltd. (Gan-Shmuel, Israel). Nutritional and chemical values of $\mathrm{CPE}$ (percent of $\mathrm{DM}$ ) were: $\mathrm{DM}=45 \%, \mathrm{CP}=2 \%$, ash $=5 \%$, total polyphenols (determined by Folin Ciocalteau reagent and expressed as gallic acid equivalent) $=10 \%$, total punicalagins $=3.3 \%$, ellagic acid $=0.2 \%$, and $\mathrm{pH}=3.2$. The final extract was standardized to ensure uniform and constant DM content (Shabtay et al., 2012). The CPE contained $0.75 \mathrm{~g} / \mathrm{L}$ of sorbate as a preservative and was kept refrigerated at $4^{\circ} \mathrm{C}$.

Statistical analysis was performed using SPSS for Windows (version 17.0). Homogeneity of variances was assessed using Levene's test and normality of distribution was tested with the Kolmogorov-Smirnov test. The FOC data in both experiments were not distributed normally, so a square-root $(+1)$ transformation was performed for the $\mathrm{H}-\mathrm{CPE}$ and L-CPE experiments. The difference of FOC between groups was tested on the average transformed FOC of all days between groups. All other parameters were distributed normally. Diarrhea intensity scores were tested on the mean score of all sampled days among groups using a Student $t$-test. Average daily gain at weaning, weight gain at $14 \mathrm{~d}$ of age, and morbidity duration were also statistically evaluated using a Student $t$-test. Data are presented as means \pm SEM. Statistical significance was declared at $P \leq 0.05$.

In the H-CPE experiment, total FOC throughout all of the sampling days in the treatment group was half of that in the control group (58.7 and 128.7 million eggs/g of feces, respectively). The average daily FOC for the entire sampling period was $2,937.3 \pm 477.3$ and $6,141.5$ $\pm 1,079.8$ thousand eggs/g of feces, in the treatment and control groups, respectively $(P=0.05$; Figure $1 \mathrm{~A})$. The diarrhea intensity showed a similar pattern to that of the daily FOC. In each of the sampling days diarrhea was more intensive in the control group, and the mean diarrhea intensity was $2.6 \pm 0.1$ and $1.6 \pm 0.1$ for the control and H-CPE calves, respectively $(P<0.001$; Figure 1B). In the L-CPE trial, no difference in oocyst shedding between groups was observed; however, the
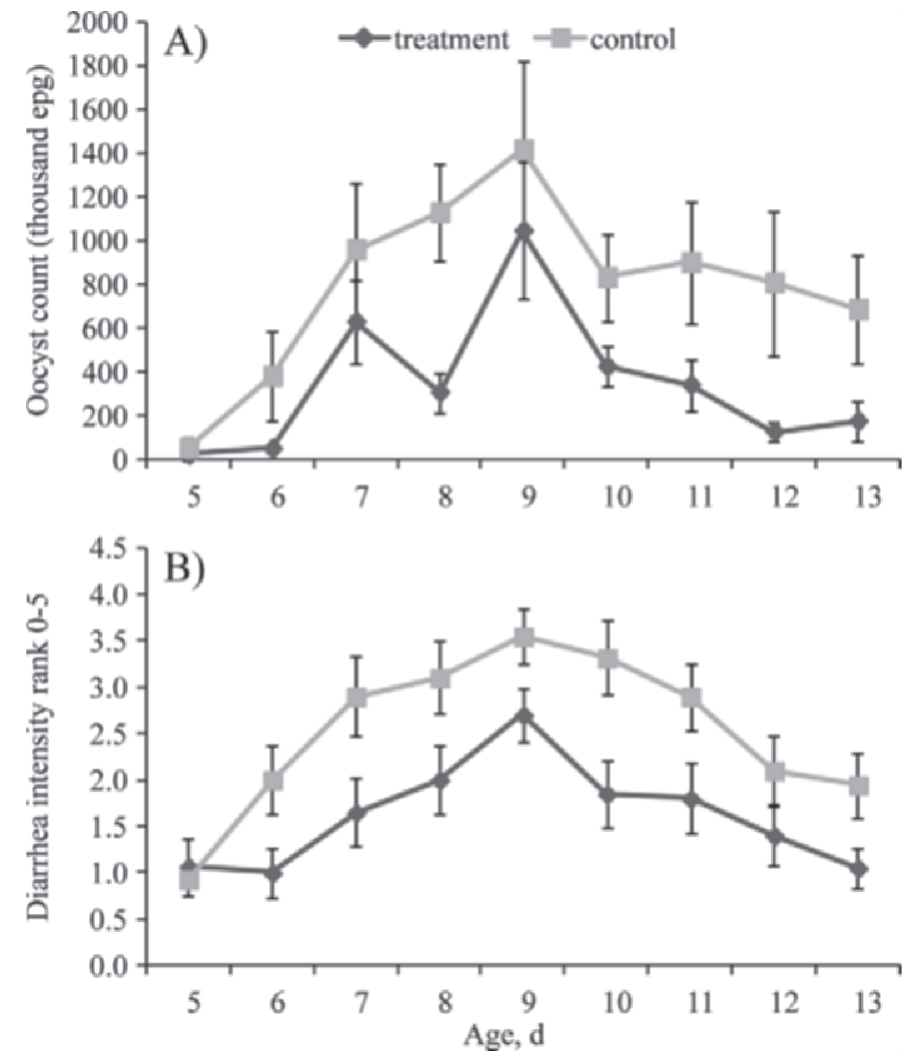

Figure 1. (A) Cryptosporidium fecal oocyst count in thousand eggs per gram (epg; $P=0.05)$ and $(\mathrm{B})$ diarrhea intensity rank $(P<0.001)$ between 5 and $13 \mathrm{~d}$ of age, following specimen collection in control (n $=20)$ and treatment $(\mathrm{n}=20)$ groups. The experiment was conducted using a $3.75 \%$ concentrated pomegranate peel extract. Data are presented as mean $\pm \mathrm{SE}$; diarrhea intensity rank: $1=$ firm, $5=$ highly watery.

mean intensity of diarrhea for all sampled days was 2.4 \pm 0.1 and $1.8 \pm 0.08$ for the control and L-CPE calves, respectively $(P<0.001)$.

Duration of diarrhea in the first experiment, in which calves received $3.75 \%$ of an extract that contained $10 \%$ polyphenols (H-CPE experiment), was $4.65 \pm 0.3$ and $2.8 \pm 0.3 \mathrm{~d}$ for the control and treatment groups, respectively $(P<0.001)$. Nevertheless, when consuming only $0.6 \% \mathrm{CPE}$ in the milk, diarrhea duration was lower compared with the control, as the mean duration of disease was $4.95 \pm 0.5$ and $3 \pm 0.4$ in the control and treatment groups, respectively $(P=0.003)$.

Average daily gain from calving to weaning in the $\mathrm{H}-\mathrm{CPE}$ experiment was $0.46 \pm 0.04(\mathrm{n}=10)$ and 0.40 $\pm 0.03(\mathrm{n}=8) \mathrm{kg}$ for males $(P=0.2)$ and $0.37 \pm 0.05$ $(\mathrm{n}=6)$ and $0.52 \pm 0.07(\mathrm{n}=8)$ for females $(P=0.1)$, for the treatment and control groups, respectively. The ADG for L-CPE at weaning was $0.37 \pm 0.03(\mathrm{n}=8)$ and $0.45 \pm 0.04(\mathrm{n}=10) \mathrm{kg}$ for males $(P=0.2)$ and $0.36 \pm 0.02(\mathrm{n}=11)$ and $0.37 \pm 0.04(\mathrm{n}=9)$ in females $(P=0.7)$, for the treatment and control groups, respec- 
tively. However, supplementation of $0.6 \% \mathrm{CPE}$ resulted in a total weight gain of $-0.5 \pm 0.64$ and $1.7 \pm 0.94 \mathrm{~kg}$ in males for the control $(\mathrm{n}=10)$ and treatment $(\mathrm{n}=9)$ groups, respectively, at $14 \mathrm{~d}(P=0.001)$; whereas, for L-CPE females, weight gain at $14 \mathrm{~d}$ of age was $0.63 \pm$ $0.6(\mathrm{n}=11)$ and $-1.11 \pm 2(\mathrm{n}=9)$ in the treatment and control groups $(P=0.4)$, respectively.

These findings suggest that $3.75 \%$ CPE supplemented in the milk of neonatal Holstein calves was effective in reducing FOC and diarrhea intensity. Those results are in line with Al-Mathal and Alsalem (2012), who demonstrated an anticryptosporidial effect induced by similar concentrations of pomegranate peel. These effects seem to provide defense from Cryptosporidium, which calves fed on milk or milk replacers alone lacked. We assume that the decrease in FOC can be attributed to the direct antiparasitical effects seen against other intestinal parasites (Landau et al., 2010; Markovics et al., 2012; Burke et al., 2013). A suggested mechanism to that phenomenon is the ability of condensed tannins to directly decrease the viability of the larval stages and disrupt egg hatching, as previously observed in nematodes (Min and Hart, 2003). In addition to the potential effect of condensed tannins, the decrease in FOC in the treatment group could be attributed to other CPE compounds. (1) Saponins (Elfalleh et al., 2012) may disrupt the protozoal membrane, inactivate enzymes, and deprive of substances and metal ions, which are essential for cell metabolism (Goel et al., 2005; Calsamiglia et al., 2007). (2) Alkaloids (Seeram et al., 2006; Elfalleh et al., 2012) have been reported to be the main factor responsible for the tanicidal effect, mostly due to the iso-pelletierine molecule they contain (Hukkeri et al., 1993). Based on that information, future research should focus on the chemical fractionation of the CPE to reveal the active components responsible for FOC decrease. Furthermore, the mode of action of these components should be investigated.

The antidiarrheal activity of CPE shown in the present study could further occur due to several mechanisms: (1) an increase in water and $\mathrm{NaCl}$ reabsorption; (2) reduced mucosal secretion; (3) inhibition of prostaglandin release from intestinal mucosa; or (4) relaxation of intestinal smooth muscles (Qnais et al., 2007).

Pomegranate extract was shown to possess antimicrobial (Rani and Khullar, 2004) and antiviral (Sundararajan et al., 2010) activities. Hence, it should be taken into account that, during the course of infectious diarrhea, CPE might also contribute to the alleviation of diarrhea, particularly because neonatal diarrhea is frequently caused by mixed infections involving Cryptosporidium and viral and bacterial agents (de la Fuente et al., 1999). In the $\mathrm{H}-\mathrm{CPE}$ experiment, calves were reared under high standard conditions. These included once-daily accession to milk and to starter ad libitum, to eat increasing amounts of dry feed for balanced development of the rumen papillae (Hopkins, 1997; Suárez et al., 2006). Indeed, at weaning this practice resulted in a mean ADG of $0.43 \mathrm{~kg} / \mathrm{d}$, which did not differ between groups in both experiments. Until recently, tannins were considered to possess only harmful effects on animal growth (Athanasiadou et al., 2001). In recent years, however, this was balanced by an increasing bulk of studies that reported low concentrations (up to 6\%, on a DM basis) of condensed tannins to be beneficial for herbivore production, including growth (Shabtay et al., 2008; Jami et al., 2012). Indeed, male calves that received $0.6 \% \mathrm{CPE}$ had a significant advantage over the control regarding their total weight gain measured at the age of $14 \mathrm{~d}$. It is likely that CPE acts positively on weight gain in the peak of morbidity via the alleviation of diarrhea intensity and duration, and probably by reduction of oxidative stress.

The results presented herein support the dietary utilization of CPE to alleviate overall intestinal morbidity. This, in turn, might further contribute to improved production in the beef and dairy industries. The use of CPE may have significant importance for herds suffering from high incidence of cryptosporidiosis and consequently help to minimize negative economic outcomes. Such a solution may be beneficial to organic farming. Although the current study showed the desired positive effects, further studies are needed to establish the optimal concentration of CPE.

\section{ACKNOWLEDGMENTS}

We thank Ein Hamifratz and Yagur Dairy Farms, Arie Yaari and Eli Budman from Gan Shmuel Food Ltd., and Tel Hai Technological College students. This research was supported by funds from the Israeli Milk Marketing Board. Contribution No. 629/13 from the ARO, the Volcani Center, Bet Dagan, Israel.

\section{REFERENCES}

Ajaikumar, K. B., M. Asheef, B. H. Babu, and J. Padikkala. 2005. The inhibition of gastric mucosal injury by Punica granatum L. (pomegranate) methanolic extract. J. Ethnopharmacol. 96:171-176.

Al-Mathal, E. M., and A. M. Alsalem. 2012. Pomegranate (Punica granatum) peel is effective in a murine model of experimental Cryptosporidium parvum. Exp. Parasitol. 131:350-357.

Athanasiadou, S., I. Kyriazakis, F. Jackson, and R. L. Coop. 2001. Direct anthelmintic effects of condensed tannins towards different gastrointestinal nematodes of sheep: In vitro and in vivo studies. Vet. Parasitol. 99:205-219.

Burke, J. M., J. E. Miller, T. H. Terrill, S. T. Orlik, M. Acharya, J. J. Garza, and J. A. Mosjidis. 2013. Sericea lepdeza as an aid in the control of Eimeria spp. in lambs. Vet. Parasitol. 193:39-46.

Calsamiglia, S., M. Busquet, P. W. Cardozo, L. Castillejos, and A. Ferret. 2007. Essential oils as modifiers of rumen microbial fermentation. J. Dairy Sci. 90:2580-2595.

Journal of Dairy Science Vol. 97 No. 9, 2014 
Cevallos, A. M., N. Bhat, R. Verdon, D. H. Hamer, B. Stein, S. Tzipori, M. E. A. Pereira, G. T. Keusch, and H. D. Ward. 2000 Mediation of Cryptosporidium parvum infection in vitro by mucinlike glycoproteins defined by a neutralizing monoclonal antibody. Infect. Immun. 68:5167-5175.

Chen, W., J. A. Harp, and A. G. Harmsen. 2003. Cryptosporidium parvum infection in gene-targeted B cell-deficient mice. J. Parasitol. 89:391-393.

Current, W. L. 1985. Cryptosporidiosis. J. Am. Vet. Med. Assoc. 187:1334-1338.

Das, A. K., S. C. Mandal, S. K. Banerjee, S. Sinha, J. Das, B. P. Saha, and M. Pal. 1999. Studies on antidiarrheal activity of Punica granatum seed extract in rats. J. Ethnopharmacol. 68:205-208.

de Graaf, D. C., E. Vanopdenbosch, L. M. Ortega-Mora, H. Abbassi, and J. E. Peeters. 1999. A review of the importance of cryptosporidiosis in farm animals. Int. J. Parasitol. 29:1269-1287.

de la Fuente, R., M. Luzón, J. A. Ruiz-Santa-Quiteria, A. García, D. Cid, J. A. Orden, S. García, R. Sanz, and M. Gómez-Bautista. 1999. Cryptosporidium and concurrent infections with other major enterophatogens in 1- to 30-day-old diarrheic dairy calves in central Spain. Vet. Parasitol. 80:179-185.

De Waele, V., N. Speybroeck, D. Berkvens, G. Mulcahy, and T. M. Murphy. 2010. Control of cryptosporidiosis in neonatal calves: Use of halofuginone lactate in two different calf rearing systems. Prev. Vet. Med. 96:143-151.

Elfalleh, W., H. Hannachi, N. Tlili, Y. Yahia, N. Nasri, and A. Ferchichi. 2012. Total phenolic contents and antioxidant activities of pomegranate peel, seed, leaf and flower. J. Med. Plants. Res. 6:4724-4730.

Fayer, R., L. Gasbarre, P. Pasquali, A. Canals, S. Almeria, and D. Zarlenga. 1998. Cryptosporidium parvum infection in bovine neonates: Dynamic clinical, parasitic and immunologic patterns. Int. J. Parasitol. 28:49-56.

Geurden, T., F. Y. Goma, J. Siwila, G. K. Phiri, A. M. Mwanza, S. Gabriel, E. Claerebout, and J. Vercruysse. 2006. Prevalence and genotyping of Cryptosporidium in three cattle husbandry systems in Zambia. Vet. Parasitol. 138:217-222.

Goel, G., A. K. Puniya, C. N. Aguliar, and K. Singh. 2005. Interaction of gut microflora with tannins in feeds. Naturwissenschaften 92:497-503.

Grinberg, A., A. Markovics, J. Galindez, N. Lopez-Villalobos, A. Kosak, and V. M. Tranquillo. 2002. Controlling the onset of natural cryptosporidiosis in calves with paromomycin sulphate. Vet. Rec. 151:606-608

Harp, J. A., and J. P. Goff. 1998. Strategies for the control of Cryptosporidium parvum infection in calves. J. Dairy Sci. 81:289-294.

Hopkins, B. A. 1997. Effects of the method of calf starter delivery and effects of weaning age on starter intake and growth of Holstein calves fed milk once daily. J. Dairy Sci. 80:2200-2203.

Hukkeri, V. I., G. A. Kalyani, B. C. Hatpaki, and F. V. Marvi. 1993. In vitro anthelmintic activity of aqueous extract of fruit rind of Punica granatum. Fitoterapia 64:69-70.

Jami, E., A. Shabtay, M. Nikbachat, E. Yosef, J. Miron, and I. Mizrahi. 2012. Effects of adding a concentrated pomegranate-residue extract to the ration of lactating cows on in vivo digestibility and profile of rumen bacterial population. J. Dairy Sci. 95:5996-6005.

Kasari, T. R. 1999. Metabolic acidosis in calves. Vet. Clin. North Am. Food Anim. Pract. 15:473-486.

Landau, S., H. Azaizeh, H. Muklada, T. Glasser, E. D. Ungar, H. Baram, N. Abbas, and A. Markovics. 2010. Anthelmintic activity of Pistacia lentiscus foliage in two Middle Eastern breeds of goats differing in their propensity to consume tannin-rich browse. Vet. Parasitol. 173:280-286.

Larson, L. L., F. G. Owen, J. L. Albright, R. D. Appleman, R. C. Lamb, and L. D. Muller. 1977. Guidelines toward more uniformity in measuring and reporting calf experimental data. J. Dairy Sci. 60:989-991.

Lassen, B., A. Viltrop, K. Raaperi, and T. Jarvis. 2009. Eimeria and Cryptosporidium in Estonian dairy farms in regard to age, species, and diarrhoea. Vet. Parasitol. 166:212-219.
Magalhães, V. J. A., F. S. Susca, A. Lima, F. Branco, I. Yoon, and J. E. P. Santos. 2008. Effect of feeding yeast culture on performance, health, and immunocompetence of dairy calves. J. Dairy Sci. 91:1497-1509.

Markovics, A., I. Cohen, H. Muklada, T. A. Glaser, L. Dvash, E. D. Ungar, H. Azaizeh, and S. Y. Landau. 2012. Consumption of Pistacia lentiscus foliage alleviates coccidiosis in young goats. Vet. Parasitol. 186:165-169.

McDonough, S. P., C. L. Stull, and B. I. Osburn. 1994. Enteric pathogens in intensively reared veal calves. Am. J. Vet. Res. 55:15161520 .

Min, B. R., and S. P. Hart. 2003. Tannins for suppression of internal parasites. J. Anim. Sci. 81:102-109.

Nagaraju, N., and K. N. Rao. 1990. A survey of plants crude drugs of Rayalaseema, Andhra Pradesh, India. J. Ethnopharmacol. 29:137-158.

Naovi, S. A. H., M. S. Y. Khan, and S. B. Vohora. 1991. Antibacterial, antifungal and anthelmintic investigations on Indian medicinal plants. Fitoterapia 62:221.

O'Donoghue, P. J. 1995. Cryptosporidium and cryptosporidiosis in man and animals. Int. J. Parasitol. 25:139-195.

Oliveira, R. A., C. D. Narciso, R. S. Bisinotto, M. C. Perdomo, M. A Ballou, M. Dreher, and J. E. P. Santos. 2010. Effects of feeding polyphenols from pomegranate extract on health, growth, nutrient digestion, and immunocompetence of calves. J. Dairy Sci. 93:4280-4291.

Ponce-Macotela, M. 1994. In vitro effect on Giardia of 14 plant extracts . Rev. Invest. Clin. 46:343.

Prakash, V., K. C. Singhal, and R. R. Gupta. 1980. Antihelmintic activity of Punica granatum and Artemisia siversiana. Indian J. Pharmacol. 12:61.

Qnais, E. Y., A. S. Elokda, Y. Y. Abu Ghalyun, and F. A. Abdulla. 2007. Antidiarrheal activity of the aqueous extract of Punica granatum (pomegranate) peels. Pharm. Biol. 45:715-720.

Quílez, J., C. Sanchez-Acedo, E. del Cacho, A. Clavel, and A. C. Causape. 1996. Prevalence of Cryptosporidium and Giardia infections in cattle in Aragon (northeastern Spain). Vet. Parasitol. $66: 139-146$.

Rani, P., and N. Khullar. 2004. Antimicrobial evaluation of some medicinal plants for their anti-enteric potential against multi-drug resistant Salmonella typhi. Phytother. Res. 18:670-673.

Santín, M., J. M. Trout, and R. Fayer. 2008. A longitudinal study of cryptosporidiosis in dairy cattle from birth to two years of age. Vet. Parasitol. 155:15-23.

Seeram, N. P., Y. Zhang, J. D. Reed, C. G. Krueger, and J. Vaya 2006. Pomegranate phytochemicals. Pages 4-14 in Pomegranates, Ancient Roots to Modern Medicine. N. P. Seeram, R. N. Schulman, D. Heder, ed. CRC Press, Boca Raton, FL.

Shabtay, A., H. Eitam, Y. Tadmor, A. Orlov, A. Meir, P. Weinberg, Z. G. Weinberg, Y. Chen, A. Brosh, I. Izhaki, and Z. Kerem. 2008. Nutritive and antioxidative potential of fresh and stored pomegranate industrial waste as novel beef cattle feed. J. Agric. Food Chem. 56:10063-10070.

Shabtay, A., M. Nikbachat, A. Zenou, E. Yosef, O. Arkin. O. Sneer, A Shwimmer, A. Yaari, E. Budman, G. Agmon, and J. Miron. 2012. Effects of adding a concentrated pomegranate extract to the ration of lactating cows on performance and udder health parameters. Anim. Feed Sci. Technol. 175:24-32.

Silverlås, C., U. Emanuelson, K. de Verdier, and C. Björkman. 2009. Prevalence and associated management factors of Cryptosporidium shedding in 50 Swedish dairy herds. Prev. Vet. Med. 90:242-253.

Silverlås, C., K. Näslund, C. Björkman, and J. G. Mattsson. 2010. Molecular characterisation of Cryptosporidium isolates from Swedish dairy cattle in relation to age, diarrhoea and region. Vet. Parasitol. 169:289-295.

Snodgrass, D. R., K. W. Angus, E. W. Gray, W. A. Keir, and L. W. Clerihew. 1980. Cryptosporidia associated with rotavirus and Escherichia coli in an outbreak of calf scour. Vet. Rec. 106:458-460.

Suárez, B. J., C. G. Van Reenen, W. J. J. Gerrits, N. Stockhofe, A. M. Van Vuuren, and J. Dijkstra. 2006. Effects of supplementing con- 
centrates differing in carbohydrate composition in veal calf diets: II. Rumen development. J. Dairy Sci. 89:4376-4386.

Sundararajan, A., R. Ganapathy, L. Huan, J. R. Dunlap, R. J. Webby, G. J. Kotwal, and M. Y. Sangster. 2010. Influenza virus variation in susceptibility to inactivation by pomegranate polyphenols is determined by envelope glycoproteins. Antiviral Res. 88:1-9.

Tripathi, S. M., and D. K. Singh. 2001. Molluscicidal activity of $P u-$ nica granatum and Canna indica combination with plant derived molluscides against harmful snails. Malays. Appl. Biol. 30:25-31.
Xiao, L. 2010. Molecular epidemiology of cryptosporidiosis: An update. Exp. Parasitol. 124:80-89.

Xiao, L., and R. P. Herd. 1994. Infection patterns of Cryptosporidium and Giardia in calves. Vet. Parasitol. 55:257-262. 